\title{
Pressure stresses generated due to supersonic steam jet induced hydrodynamic instabilities
}

\author{
Afrasyab Khan a,*, Khairuddin Sanaullah ${ }^{\mathrm{a}}$, Mohd. Sobri Takriff ${ }^{\mathrm{b}}$, Hushairi Zen ${ }^{\mathrm{c}}$, \\ Andrew Ragai Henry Rigit ${ }^{\mathrm{d}}$, Ajmal Shah ${ }^{\mathrm{e}}$, Imran Rafiq Chughtai ${ }^{\mathrm{f}}$, Tahir Jamil ${ }^{\mathrm{g}}$ \\ ${ }^{a}$ Faculty of Engineering, Department of Chemical Engineering E Energy sustainability, University Malaysia Sarawak (UNIMAS), P.O. Box: 94300, Kota \\ Samarahan, Sarawak, Malaysia \\ ${ }^{\mathrm{b}}$ National University of Malaysia (UKM), Faculty of Engineering E Built Environment, Department of Chemical E Process Engineering, P.O. Box: 43600, \\ Bangi, Selangor, Malaysia

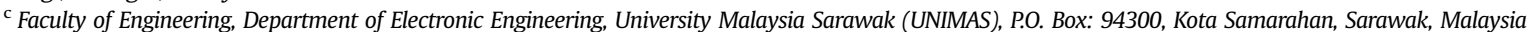 \\ ${ }^{\mathrm{d}}$ Faculty of Engineering, Department of Mechanical E Manufacturing Engineering, University Malaysia Sarawak (UNIMAS), P.O. Box: 94300, Kota Samar- \\ ahan, Sarawak, Malaysia \\ e Department of Mechanical Engineering, Pakistan Institute of Engineering \& Applied Sciences (PIEAS), NILOR, Islamabad, Pakistan \\ ${ }^{\mathrm{f}}$ Department of Chemical Engineering, Pakistan Institute of Engineering E Applied Sciences (PIEAS), NILOR, Islamabad, Pakistan \\ ${ }^{\mathrm{g}}$ Institute of Chemical Engineering \& Technology, Punjab University, Lahore, Pakistan
}

\section{H I G H L I G H T S}

- Hydrodynamic instabilities emerged both in axial as well as radial direction.

- Instabilities created at the steam water interface and propagated towards the walls.

- These instabilities produce pressure stresses in a non-deterministic way.

- Both hydrodynamic instabilities and their induced stresses are asymmetric in nature.

- The strength of these instabilities varies along radial as well as axial directions.

\section{A R T I C L E I N F O}

\section{Article history:}

Received 18 February 2015

Received in revised form

11 December 2015

Accepted 21 January 2016

Available online 20 February 2016

Keywords:

Hydrodynamic

Instabilities

Stress

Steam

Water

Pressure

\begin{abstract}
A B S T R A C T
The phenomenon that involves direct contact of steam with water is called Direct Contact Condensation (DCC). This phenomenon has been observed/prevailed in most of the power and process industries. The phenomenon of direct contact condensation involves heat, mass and momentum transfer across the highly fluctuating interface between steam jet and surrounding water giving this process an intricate nature to be studied. More recently the observation of hydrodynamic instabilities at the interface between supersonic steam jet and water has given a new facet to the study of DCC. In the current study the equivalent von-Mises Stress, equivalent elastic strain and total deformation in the Perspex vessel that has been incurred due to the pressure stresses has been studied. These pressure stresses have been generated due to the condensing supersonic steam jet induced hydrodynamic instabilities. It has been investigated first by experimentally observing the temperature fluctuations in axial and radial directions across supersonic steam jet which actually depicts these instabilities. Then Direct Contact Condensation (DCC) model has been used to conduct the CFD study using a commercial code Ansys ${ }^{\infty}$. Accompanied with this a mock up study has been done in which the pressure loads computed using DCC model have been coupled to the Perspex vessel structure using one way Fluid Structure Interaction (FSI) analysis in Ansys $^{\text {it }}$ to compute the true scale equivalent von-Mises Stress, equivalent elastic strain and total deformation generated by hydrodynamic instabilities induced pressure stresses. On true scale, hundreds of Pico scale deformation has been computed in the Perspex vessel confinement.
\end{abstract}

(c) 2016 Elsevier Ltd. All rights reserved.

\footnotetext{
* Corresponding author.

E-mail addresses: 12010046@siswa.unimas.my (A. Khan), skhairuddin@feng.unimas.my (K. Sanaullah), sobritakriff@ukm.edu.my (Mohd.S. Takriff), zhushair@feng.unimas.my (H. Zen), arigit@feng.unimas.my (A.R.H. Rigit), ajmal@pieas.edu.pk (A. Shah), imran@pieas.edu.pk (I.R. Chughtai), tahirj4@yahoo.com (T. Jamil).
}

\section{Introduction}

The wheel of the present age industrial progress drives by energy. In a most recent review conducted by US Department of 